Bulletin d'Histoire Contemporaine de I'Espagne

$54 \mid 2020$

Les espaces du politique dans l'Espagne du Trienio liberal (1820-1823)

\title{
«Sable en mano, con la cruz a cuestas». Las reacciones y los espacios del clero católico ante el Trienio Liberal
}

«Sabre au clair, la croix sur l'épaule». Les réactions et les espaces du clergé

catholique face au Triennat libéral

"Sabre in he hand, the croos on the shoulder». The reactions and spaces of the

Catholic clergy to the Liberal Triennial

\section{Gregorio Alonso}

\section{(2) OpenEdition}

Journals

Edición electrónica

URL: http://journals.openedition.org/bhce/2488

DOI: 10.4000/bhce.2488

ISSN: 1968-3723

Editor

Presses Universitaires de Provence

Edición impresa

Fecha de publicación: 1 enero 2020

ISSN: 0987-4135

Referencia electrónica

Gregorio Alonso, « «Sable en mano, con la cruz a cuestas». Las reacciones y los espacios del clero católico ante el Trienio Liberal », Bulletin d'Histoire Contemporaine de l'Espagne [En línea], 54 | 2020,

Publicado el 01 julio 2020, consultado el 01 enero 2021. URL : http://journals.openedition.org/bhce/ 2488 ; DOI : https://doi.org/10.4000/bhce.2488

Este documento fue generado automáticamente el 1 enero 2021.

Bulletin d'histoire contemporaine de l'Espagne 


\title{
«Sable en mano, con la cruz a cuestas». Las reacciones y los espacios del clero católico ante el Trienio Liberal
}

\author{
«Sabre au clair, la croix sur l'épaule». Les réactions et les espaces du clergé \\ catholique face au Triennat libéral \\ "Sabre in he hand, the croos on the shoulder». The reactions and spaces of the \\ Catholic clergy to the Liberal Triennial
}

\section{Gregorio Alonso}

1 El protagonismo del clero en las luchas políticas durante el establecimiento del régimen constitucional, y la ambivalencia y mutabilidad de sus posiciones ha sido estudiado en detalle por especialistas como Emilio La Parra, Antonio Moliner, Manuel Revuelta, Pedro Rújula o William Callahan ${ }^{1}$. Sus reflexiones y hallazgos investigadores siguen inspirando la reconstrucción historiográfica de las complejas relaciones entre el liberalismo y el catolicismo en la España peninsular. En este artículo tras una breve reflexión sobre la relación entre religión y violencia, me centraré en analizar una selección de textos que exploran el surgimiento y consolidación de clero contrarrevolucionario en las décadas de 1810 y 1820 en España. La primera sección da cuenta de las respuestas del clero reaccionario ante la aprobación de las reformas eclesiásticas durante el Trienio, con especial atención a la llamada ley de monacales de septiembre de 1820. Después se presentan algunas visiones alternativas expresadas entonces que escapan al binomio clero liberal/ clero reaccionario. En una tercera parte se analizan las tensiones previas a la creación de la Junta de Urgel, y en la última sección se avanzan algunas consideraciones sobre el carácter de la violencia política contrarrevolucionaria perpetrada por algunos miembros del clero regular en el contexto de la creación de aquella primera fuerza internacional de paz que fue la Santa 
Alianza² ${ }^{2}$ En cada sección se pondrá énfasis en los espacios de acción privilegiados por el clero.

El curso de la primera restauración fernandina iniciada el 4 mayo de 1814 con el decreto de Valencia no estuvo exento de episodios violentos. En muchos casos, merced a la participación del clero y a la justificación sobre presuntas bases teológicas, la represión tuvo rasgos de sacralización de la política y de la propia intimidación depuradora ${ }^{3}$. Más de dos siglos después, los vínculos entre la religión y la violencia sigue estimulando encendidos debates académicos, periodísticos e incluso parlamentarios. Uno de los pioneros de esta área de estudios fue el historiador y antropólogo filosófico franco-estadounidense René Girard. Su libro de 1972, La violence et le sacré, es una referencia obligada para abordar dicha conexión. Sus posteriores trabajos sobre la capacidad redentora del ritual violento y el papel del sacrificio como puente hacia la divinidad amplían y profundizan su original concepción de la dimensión religiosa de la vida social y su papel mediador en los conflictos. Para adentrarse en ella convendría destacar primero su definición de religión. Partiendo de una antropología pesimista en la que los seres humanos se ven animados primordialmente por su instinto agresivo y destructor, Girard define la religión como una cura o un fármaco. Para Girard, la función primigenia de los rituales religiosos ha sido históricamente dar salida a ese instinto autodestructor que a todos nos impulsa. Con sus propias palabras, la «religión en su sentido más amplio debe entenderse como un término alternativo para referirse a la oscuridad que rodea a los esfuerzos de los hombres para protegerse de su propia violencia por medios curativos o preventivos» ${ }^{4}$. Amplios sectores del clero español parecieron compartir esa visión por lo que se pudo constatar también durante el segundo proceso de restauración absolutista.

\section{Del púlpito y las calles a los despachos y el parlamento}

3 Tanto en 1814 como en 1823 un alto número de clérigos repartieron medicamentos ultraterrenos y contrarrevolucionarios que hallaron en la referida farmacia religiosa. Sirva de punto de partida la espectacular entrada en la Corte del sacerdote y veterano guerrillero Jerónimo Merino encabezando su facción. Una multitud enfervorecida se dio cita en el centro de Madrid para recibirlo. A lomos de un mulo, con un sable en ristre y un fusil en el cinto, el cura Merino se dio un baño de multitudes, como insigne miembro de aquella gran familia que formaban los cien mil hijos de San Luis. Merino ya era un viejo conocido de los madrileños y bastante popular, a decir de algunos autores. Por ejemplo, su biógrafo Eduardo Ontañón lo describe con vivos colores: «La verdad es que Merino, en Madrid, por aquella primavera de 1814, fue algo así como la atracción de forasteros. Las cosas que se habían contado de él, los relatos de su talante, las hazañas que se describían en las coplas de ciego, los cuentos, las caricaturas... Todo rodeaba a Merino de una perfecta aureola para los papamoscas. Le seguían por las calles como sólo se sigue a los toreros y a los futbolistas» ${ }^{5}$. Como se verá más tarde, la incorporación del cura Merino a las fuerzas realistas alzadas contra la constitución a finales de 1820 había sido decisiva en la escalada de la rebelión, habida cuenta de su capacidad de liderazgo militar. Bajo sus órdenes se pusieron nutridos grupos de realistas cuyo tamaño desbordaría el de las meras partidas aisladas, sobre todo en Navarra, el Maestrazgo y el norte de Castilla. 
4 La destrucción del sistema constitucional, sin embargo, se había ido fraguando también en otros lugares. En concreto, en las embajadas, salones y gabinetes de las principales capitales del continente desde 1820. La Europa post-napoleónica observaba con mucha atención los acontecimientos en España, sobre todo en los territorios dominados por la dinastía borbónica ${ }^{6}$. Los gabinetes centroeuropeos vieron con pavor el contagio revolucionario que se estaba produciendo en el sur y el este de Europa, y no perdieron tiempo en organizarse para ponerle coto. Para ello la contrarrevolución contaba también con la ambigua anuencia de los servicios diplomáticos británicos, que actuaron a conveniencia como mediadores, aliados y fuente de información ${ }^{7}$. Hace ya una década que Emilio La Parra reconstruyó con su habitual finura los antecedentes, desarrollo y consecuencias de la intervención de las potencias restauradoras en la vida política española. En su trabajo se presta especial atención a las dimensiones internacionales del conflicto y a la revolución mediterránea que desafiaba aquella Santa Alianza formada en los congresos de Troppau y Verona ${ }^{8}$. Obras posteriores han abundado en la misma dirección aportando nuevos detalles sobre la escalada de revueltas populares y anti-imperiales que agitaron la Europa meridional en la década de 1820. También se ha reflexionado sobre los desesperados intentos de los diferentes gobiernos del Trienio para estabilizar sus relaciones con las potencias no hostiles y consolidar así el régimen constitucional $^{9}$. La diplomacia europea era muy consciente de que el foco irradiador era España y que los episodios insurreccionales de Portugal, Nápoles, Piamonte, Grecia y Rusia encontraron en la Constitución de Cádiz el hilo que las trenzaba ${ }^{10}$. Por tanto, tras la caída del régimen constitucional en los territorios transalpinos, la Santa Alianza dejó en manos del gobierno francés el golpe de gracia al régimen constitucional en España tras haberlo derrocado en Nápoles, contando para ello con el apoyo de numerosos eclesiásticos. Así, Benito Pérez Galdós en el Episodio Nacional donde retrató la caída del régimen en 1823 puso de manifiesto el protagonismo del clero regular en la resistencia realista contra el liberalismo en Cataluña y otras regiones de España: «Muchos frailes del país, empezando por los aguerridos capuchinos de Cervera que habían escapado del furor de las tropas liberales, y concluyendo por los monjes de Poblet que tanto trabajaron en la conspiración, formaban en las filas del Manco, o de Capapé o de Misas» $»^{11}$.

5 Nueve años antes Fernando VII ya había derogado la Constitución y cerrado a perpetuidad las Cortes. Este era el mundo donde el cura Merino se encontraba en la gloria terrenal. Pero ¿de dónde procedía aquel inquebrantable furor antiliberal de algunos clérigos? Un autor tan poco sospechoso de liberalismo como Melchor Ferrer ofrece pistas importantes. En su famosa Historia del Tradicionalismo español, la obra de 40 tomos escritos a seis manos con Domingo Tejera de Quesada y José Francisco Acedo, y bajo la protección de Manuel Fal Conde, asegura que ya en 1814: «Mientras se detenía a los diputados y elementos destacados del liberalismo, se recompensaba a los diputados y militares que habían mantenido su lealtad a los principios tradicionales de España. Así, los eclesiásticos recibían: Ros de Medrano, la mitra de Tortosa; Cañedo la de Málaga; Creus, la de Mallorca, Inguanzo, la de Zamora, y Pérez la de Puebla (México)» ${ }^{12}$.

6 La mano derecha de Cañedo en Málaga, el canónigo ultra Juan Buelga defendió a menudo desde el púlpito sus valores contrarrevolucionarios. La teología política reaccionaria inspiró ya en enero de 1820 su «Prevención contra los enemigos ocultos del Estado y de la Religión», predicada en la catedral y publicada en la ciudad de Málaga poco después del éxito de la revolución. En ella afirmaba que los soldados y oficiales 
alzados en Cabezas de San Juan era traidores y reos de lesa patria. En su sermón afirmó: «Todo gobierno y sociedad legitima se estremece y llena de horror, cuando llega a conocer que dentro de sus límites se ocultan enemigos armados para su destrucción» ${ }^{13}$. A los revolucionarios se les vituperaba en una misa mayor con furor y desmesura. Se les atribuía todo tipo de crímenes y sus destructoras intenciones que ponían en riesgo no sólo el altar y el trono, sino la sociedad en su conjunto. Para Buelga: «La patria cubierta de sangre sería para ellos un jardín; un placer ver hollada toda autoridad; una alegría extremada mirar ultrajado el clero, degradado el noble, empobrecido y andrajoso el propietario y acaudalado» ${ }^{14}$.

7 Tras haber sido un actor fundamental del sistema represivo de restauración de la llamada plena soberanía regia durante el sexenio anterior, el clero vio con preocupación el regreso al régimen constitucional. A tenor de las decisiones tomadas en Cortes en octubre de 1820 en la aprobación de la Ley de Monacales, sus temores parecían justificados. Por el decreto XLII del primero de octubre de 1820, las Cortes presididas por el Conde de Toreno suprimían todos los monasterios de las órdenes monacales y militares, así como los beneficios asociados a los mismos, aunque los «poseedores de curatos, prebendas, encomiendas, oficios $u$ otros cualquiera de representación real, continuarán en el ejercicio y disfrute de ellas. A los monjes ordenados in sacris se les adjudicaban pensiones que oscilaban entre los 300 y 600 ducados, similar cantidad a los monjes hospitalarios o miembros de las órdenes militares, y a los monjes profesos entre 100 y 200, dependiendo de la edad». Se impedía la fundación de nuevos conventos, se dictaba que hubiera solo una casa religiosa de la misma orden en cada población, y prohibía la ordenación de nuevos monjes, y se facilitaba la secularización de todos aquellos religiosos que lo solicitaran mediante la concesión de una congrua de 100 ducados. Por otro lado, toda congregación de menos de 24 miembros debía de unirse a la del convento más cercano de la misma orden y, en aquellos pueblos que no hubiera más que un convento, podrían seguir abiertos aquellos que contaran con un mínimo de 12 miembros. Los bienes de los conventos suprimidos se aplicarían al crédito público. Para Buelga aquella reforma había confirmado los peores temores del clero. Tres años después, en un memorándum donde se recogían los atropellos a los que decía haberse visto sujeto bajo el régimen constitucional, declaraba rotundamente que «cuando la impiedad revolucionaria levantó el grito en 1820, dirigió sus primeros ataques contra el Trono, y después de encadenar a un Monarca legítimo, descargó su furor y rabia sobre el Clero» ${ }^{15}$.

8 En términos similares se expresaría Melchor Ferrer en el tomo III de la Historia del tradicionalismo español. Lo hizo siguiendo a pies juntillas la interpretación reaccionaria de Buelga y también definió la Ley de Monacales aprobada en Cortes como persecución al clero. Al sistema constitucional, pese a que seguía declarando que la forma de estado sería una monarquía católica intolerante, se lo motejaba de perseguidor de la Corona y la Iglesia: «La persecución religiosa se hacía con la oposición del Rey y la protesta de los prelados, religiosos, sacerdotes y católicos en general. Contra el Rey, se empleaba la coacción; contra los religiosos, la persecución $»^{16}$. Ferrer ilustraba esta segunda acusación refiriéndose a los casos de Francisco de Solchaga, padre general de la orden de los Capuchinos, que fue condenado al destierro por verter opiniones anticonstitucionales. Este prelado navarro se opuso a la intervención del poder civil en la organización interna de la orden religiosa que dirigía. La imposición del cierre de 
casas religiosas y la elección directa de los generales de las órdenes religiosas encendió sus ánimos y lo llevó a escribir una Observación respetuosa a las Cortes ${ }^{17}$.

9 A partir de 1823, con el segundo un proceso restaurador que supuso de nuevo el destierro y la prisión de miles de españoles, la figura del liberal «arrepentido» se convertiría en una figura habitual en los folletos y hojas volanderas producidas por los escritores contrarrevolucionarios. Desde entonces la identificación del liberalismo con luchas contra el catolicismo romano propagada por la masonería y el judaísmo se consolidarían como lugar común ${ }^{18}$. No obstante, dicha caracterización y su capacidad movilizadora antiliberal presentaba flancos descubiertos difíciles de proteger, dado que no todas las iglesias, sacristías y confesionarios se habían puesto al servicio de la revolución.

\section{Un clero dividido ocupa templos, redacciones y salones}

Como viene señalando Álvaro París Martín en los últimos años, entre otros, los grupos contrarrevolucionarios de la Europa post-napoleónica compartían con los revolucionarios idénticos mimbres de modernidad. Es decir, la reacción popular contra los supuestos excesos perpetrados durante el Trienio, sus prácticas discursivas y sus dinámicas movilizadoras compartieron mecanismos y estrategias con los sectores liberales ${ }^{19}$. En efecto, la edición hace casi tres décadas de los Sermones revolucionarios del Trienio Liberal a cargo de Gérard Dufour apuntaba ya en esa dirección, pero en sentido contrario ${ }^{20}$. Es decir, mientras que las nuevas tendencias señalan que los contrarrevolucionarios se valieron de los herramientas, el léxico y los espacios revolucionarios para acabar con la revolución; Dufour resaltaba que también los liberales recibieron el apoyo de un clero supuestamente opositor a las reformas que propugnaban y que hubo también clérigos que se sirvieron de los espacios eclesiales y de la oratoria sagrada para defender los avances de la revolución. La existencia de clero liberal en España a la altura de 1820 no constituía novedad alguna. Sacerdotes, obispos y cardenales de renombre, como Juan Antonio Llorente, Antonio Puigblanch, o los hermanos Jaime y Joaquín Lorenzo Villanueva, ya habían abrazado las ideas reformistas en el primer periodo constitucional ${ }^{21}$. A ese grupo perteneció el abate José Marchena, exiliado político y traductor de Voltaire, que apoyó las reformas en su famoso «Discurso sobre la ley relativa a la extinción de monacales y reforma de regulares» de 1820. En esta ocasión, por lo que se refiere a la presencia y uso por parte del clero de espacios civiles, el clérigo expuso sus ideas en uno de los lugares privilegiados de la sociabilidad liberal. Apenas un mes después de que se aprobara la reforma, y ante los congregados en la sociedad patriótica Constitucional hispalense, el abate utrerano desgranó sus argumentos en defensa de las modificaciones introducidas por las Cortes ${ }^{22}$.

11 Marchena consideraba la desamortización de las tierras del clero regular un gran acierto político: «Porque ¿a quién se pueden esconder los perjuicios que a España redundaban del estanco de inmensas fincas en manos muertas, la posesión de abundantísimas riquezas en premio de la ociosidad, o de faenas totalmente inútiles para el cuerpo social, tantos capitales sacados de la circulación, enterrados en lo interior de los santuarios (...)?»²3. Para Marchena, la venta de las fincas de los monasterios había dado ocasión a clérigos como Solchaga a propalar doctrinas contrarias a las enseñanzas de las Sagradas Escrituras y fundadas exclusivamente en la 
desesperada salvaguarda de sus intereses individuales y corporativos: «A tanto ha llegado el fanatismo que ha dicho que eran sagradas las propiedades eclesiásticas, porque los fundadores de obras pías han hecho sus donaciones al mismo Dios; aserto en que la blasfemia se apuesta con la necedad $»^{24}$.

Serían tan necios y blasfemos como Marchena quisiera, pero los enemigos del liberalismo se organizaron velozmente, y ya en 1820 participaron en las revueltas ultra realistas. En efecto, la oposición violenta al gobierno y la formación de partidas comenzaron en noviembre, primero en Álava, Ávila y después en Burgos. Como recuerda Ferrer, la rebelión se extendería a varias comarcas asturianas y, desde principios de diciembre, a Galicia. Allí su líder, Manuel de Castro, sería preso en la villa de La Torre, en la provincia de Orense, e inmediatamente fusilado en La Coruña ${ }^{25}$. El devenir de los acontecimientos y la dinámica de acción realista-reacción constitucionalista llevó el foco de la acción a Madrid. Sería otro clérigo el que tomó protagonismo, el famoso cura de Tamajón, Matías Vinuesa. Según Ferrer, Vinuesa había trazado un plan por el que los madrileños más afectos al absolutismo se unirían contra las sociedades patrióticas y el código de 1812 al grito de «iViva la Religión, viva el Rey y la Patria y muera la Constitución!». El plan incluía el apresamiento de destacados liberales, incluyendo a varios diputados, y su confinamiento en el Castillo de Villaviciosa de Odón, en las cercanías de la capital ${ }^{26}$. El plan fue descubierto y el cura recluido en la cárcel de Corte el 28 de enero de 1821, tras encontrar en su casa documentación que lo inculpaba personalmente ${ }^{27}$. Vinuesa fue condenado a 10 años de prisión mientras que las sociedades patrióticas y los grupos de exaltados madrileños clamaban por su vida. En la tarde del 4 de mayo, un grupo de exaltados entraría en su celda para asesinarlo sin piedad. La investigación de Marta Ruíz Jiménez, basada en los expedientes policiales y judiciales generados por el caso, ha puesto de manifiesto la participación en el asesinato de elementos cercanos a la camarilla del rey. Según Ruíz Jiménez, en mayo «los absolutistas vieron el momento oportuno para crear un mártir al tiempo que desacreditar el sistema liberal-constitucional». Dos años después, en junio de 1823, se cursaría causa contra cuatro de los participantes en el crimen, que habían salido del café del Ángel, situado en la plaza del mismo nombre, y tres de ellos fueron ahorcados, mientras que uno de ellos logró escapar ${ }^{28}$.

Estos hechos se dieron en un momento en que las redacciones de los periódicos se convirtieron en espacios privilegiados de la lucha política. Gracias a los trabajos de Elisabel Larriba tenemos conocimiento detallado del uso que la prensa había hecho el clero católico durante las décadas anteriores ${ }^{29}$. Teniendo en cuenta sus recomendaciones, se analizará a continuación el contenido de una publicación del periodo para constatar su actualidad durante el Trienio y la existencia de áreas grises que otorgaron complejidad a la recepción de las medidas parlamentarias y gubernamentales en materias eclesiásticas. En 1820 aparecía el primer número de $\mathrm{El}$ ciudadano despreocupado, un diario monárquico, clerical y conservador de Sevilla, en cuyo número señalaba la continuidad existente entre el periodo de restauración de plena soberanía regia y el apenas recuperado régimen constitucional: «Dependemos siempre de las Leyes y del Rey, y estamos obligados por nuestro juramento a obedecer. No hay Tribunal de Inquisición, es verdad, pero hay obispos que juzguen de lo que juzgaba. No hay más Consejo que el de Estado, pero hay un Tribunal Supremo de Justicia, que conoce y sentencia según derecho. Hay libertad para que todo ciudadano publique sus ideas políticas; pero no la hay para escribir y hablar contra el dogma y disciplina». Y concluía: «Somos Ciudadanos libres, es cierto; pero subordinados a las 
determinaciones del Congreso. Pagábamos contribuciones, las pagaremos también y debemos pagarlas. Dábamos nuestros hijos, nuestros hermanos, nuestros parientes á la milicia, los daremos en la forma y cuando fueren llamados por la Ley. Sí, la Constitución, la sabia Constitución de nuestra Monarquía no autoriza el vivir según la voluntad del Ciudadano: si así fuese sería un monstruo, y no un Código qué dulcemente obliga a obrar según el recto dictamen de la razón. Tendrá acaso defectos que corregir, capítulos que reformar, artículos que variar o a derogar; pero siempre queda firme que el Ciudadano español, aunque libre, está sujeto a la Ley». Pese a la resignada aceptación del sistema constitucional, el tono del escrito era muy escéptico con respecto a sus virtudes y principios fundantes. De hecho, el artículo se abría diciendo: «La libertad, la independencia, que se han figurado tantos, y tan mal han entendido, es quimérica, es ideal» ${ }^{30}$.

Que la libertad era quimérica bajo el régimen constitucional restaurado era patente por las limitaciones impuestas en el decreto de libertad de imprenta de noviembre de 1811. Las limitaciones impuestas al ejercicio de la libertad de prensa tenían como objeto precisamente la defensa de la religión católica y, una vez cerrado el Santo oficio, a los obispos ordinarios se les encomendaba la censura eclesiástica de todas las publicaciones que abordaran temas religiosos o eclesiásticos. Así lo señalaban los autores de $\mathrm{El}$ Ciudadano cuando recordaban a sus lectores que: «aunque somos ciudadanos libres, no somos libres para escribir y; publicar ideas Anti-políticas, anti-sociales anti-religiosas, anti-cristianas, anti-monacales, anti-constitucionales ${ }^{31}$.

Los contenidos de esta publicación muestran con claridad la doble estrategia seguida por los defensores del orden anterior: legalista e insurreccional. Por un lado, resulta llamativo que los autores del periódico defendieran desde este primer número la elección de Vocales a Cortes que secundaran su ideario de corte tradicional: «Nombremos hombres que miren siempre por la mayor gloria y exaltación de nuestra Santa Religión Católica, Apostólica Romana, única, verdadera, por la obediencia y protección de la Iglesia y sus Ministros, por el Sucesor de Pedro, por la conservación y aumento de nuestras, instituciones piadosas: hombres cuyas opiniones hayan sido siempre, y sean las más sanas, pías y religiosas». Y su desiderátum se cerraba exigiendo a esos representantes de la nación que evitaran la confusión de las causas civiles con las religiosas y que, amantes del altar y el trono, fueran «hombres que actúen sin haber confundido jamás lo sagrado con lo profano, ni lo espiritual con lo político. Que impidan con infatigable celo los insultos de algunos, que so color de ilustración, y por medios tortuosos traten o intenten socavar los fundamentos de un edificio labrado y fundado con la sangre del mismo Jesucristo, y bajo el especioso título de reforma quieran dar a otros lo que no es suyo, quitando a Dios lo que le pertenece, y le es tan propio. Nombremos hombres que conserven el amor, respeto y veneración al Rey, su autoridad, sus prerrogativas, sus preeminencias $»^{32}$.

En el segundo número El Ciudadano también arremete contra los autores de un folleto titulado «El Amante de la Constitución», publicado también en Sevilla. La denuncia se dirigía contra aquellos «enemigos de la Religión y de los Sacerdotes regulares, de quienes dice son una turba de Frailes inútiles y aun perjudiciales, ya por su número ya por la poca observancia de su instituto, que acaso serían útiles en la época de su fundación y de ninguna manera al presente. Que son enemigos de la religión una porción de Frailes que han profanado sacrílegamente el Sagrado Texto, que han ajado groseramente los Sagrados Evangelios, que han manchado la pureza de la religión 
revelada con un gran número de falsas historias, de indecentes patrañas, de supuestos milagros y abominables supersticiones. Que son los mayores enemigos de Dios el mal prelado, el canónigo distraído y el mal eclesiástico» ${ }^{33}$.

17 Se rechazaban todas las acusaciones contra los clérigos y se mostraba también desprecio a todos los partidos políticos, rindiendo pleitesía a las potencias aliadas por su apoyo en la derrota de Napoleón. Asimismo, se denunciaba a los supuestos culpables de los males de la patria:

18 «Los enemigos pues de la Religión y de Dios, no son los Frailes, ni los Prelados Eclesiásticos, ni los Clérigos: los son en verdad los incrédulos, los impíos, los Jacobinos, los Masones, los herejes. Esos son los que con sus doctrinas y perversas opiniones seducen y engañan al pueblo, apartándolo de la fe, de la obediencia, del respeto y veneración que debe a la Religión revelada. Los son los Serviles y Liberales que, separándose de los senderos de la verdad, ni piensan ni viven según el espíritu del Evangelio. Los son en fin los que olvidando y despreciando a Dios y sus atributos, se empeñan y tratan de destruir aun por medios tortuosos el grande y magnífico edificio de la Iglesia, y Vuestra Majestad también si así lo hace, y son estos sus intentos. No son ideas políticas decir que la libertad que recobró Fernando la debe solo a nuestros bríos, y no a las mentidas preces de los Frailes. ¿Conque la libertad que recobró Fernando la debe sólo a nuestros bríos? ¿Pues para qué imploramos el auxilio y fuerzas de Inglaterra, Portugal, Sicilia y Rusia? ¡Ah! quizá pelearíamos o hubiéramos sufrido la suerte de Sagunto» ${ }^{34}$.

19 La más encendida defensa del trono y el altar se hacía necesaria en un momento en que el gobierno constitucional, siempre desde el punto de vista reaccionario, los sometía y les privaba de sus recursos materiales y espirituales. Así, el periódico sevillano denunciaba la falta de civismo de las autoridades asegurando que: «no son ideas políticas atacar y amenazar a nuestro amado Rey Fernando primer Ciudadano de la Nación, cuya persona es sagrada, es inviolable; como tampoco lo es proponerle, bajo el pretexto de socorrer la urgente necesidad, exija del Clero, que llama opulento, un préstamo obligatorio por usar, y usando al mismo tiempo de la calumniosa impostura de que así se le quitan las armas con que nos está haciendo la guerra; cuando las armas del Cielo son espirituales, y no sus decantadas riquezas, y hace guerra con aquellas, no a la Nación sino a las potestades del abismo, a los enemigos de la Religión y a sus secuaces, -para que no prevalezcan ni consigan lo que intentan» ${ }^{35}$.

20 Ante semejante presión, del mismo modo que el monarca recurría a los monarcas absolutos, el alto clero se vio impelido a apelar al socorro del papa. Pio VII envió una carta a Luís de Borbón, arzobispo de Toledo, el 30 de mayo de 1820, en respuesta a otra que el prelado toledano había enviado al Papa mostrando su preocupación por las reformas eclesiásticas. El Papa respondió dando seguridades de su eterno celo por el estado del catolicismo en España, pero sin avanzar acción concreta alguna. Ante la vaguedad de las recomendaciones pontificias, el temor y rechazo a las reformas se instalaron entre los prelados como reflejó el arzobispo de Zaragoza en su carta al Papa Pio VII el 13 de noviembre de 1820: «La inmunidad eclesiástica real y personal destruidas por otro decreto, en que se declara que los individuos del Clero en materia criminal deben estar sujetos a los jueces civiles, ser juzgados como legos sin ninguna intervención de la jurisdicción eclesiástica, y ser castigados como tales cubriéndoles la corona para que no se conozca su jerarquía» ${ }^{36}$. En pocos meses se iniciaría la campaña para luchar contra el gobierno por la fuerza de las armas y la contrarrevolución 
encontraría sus líderes armados en ciertos clérigos veteranos de la pasada guerra contra la ocupación francesa.

\section{Al campo de batalla}

21 El uso político de la religión para sacralizar del derramamiento de sangre ha sido ampliamente estudiado por antropólogos, filósofos, politólogos, historiadores y

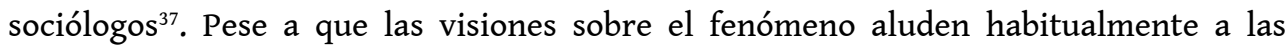
interpretaciones sesgadas que se hace de las creencias ultraterrenas de la población a cargo de las elites dirigentes con el objeto de justificar el uso de la fuerza contra el enemigo, también cuestionan la propia definición de política y de religión al uso. En este sentido son recurrentes las críticas al presentismo, etnocentrismo y sesgo orientalizante que informa algunos de estos trabajos. Para autoras como Barbara Ehrenreich, el recurso a la religión presente en la sacralización de la violencia de las sociedades preindustriales se ve suplantado por los discursos nacionalistas en periodos más recientes ${ }^{38}$. Sea como fuere, la lucha contra el sistema constitucional en la España de la década de 1820 se hizo en nombre de la defensa de la fe heredada y la lideraron clérigos entusiastas y radicalizados por reformas que consideraban afrentas.

Así el ya referido autor Eduardo de Ontañón, citando a otro biógrafo de Merino, Eulogio Ruiz de Casaviella, recuerda la importancia que se le otorgó al fervor religioso para justificar desmanes y barrabasadas: «Lanzábanse al combate impulsados por un religioso entusiasmo, teniendo por un servicio hecho a la religión el matar a sus conciudadanos enemigos ${ }^{39}$.

Ante tales desmanes, los sectores liberales también entraron en la liza y propagaron sus ideas en los periódicos y en los cafés. A la hora de entender la defensa de sus políticas eclesiásticas conviene recuperar el modo en que Girard abordaba el hecho religioso citado al inicio de este artículo. Su definición resulta plenamente compatible con la que había hecho el abate José Marchena en su discurso sevillano de 1820 «el principal objeto de la religión es sancionar con sobrenaturales castigos y premios las leyes naturales, las cuales todas se refieren a la conservación y perfección del orden social» ${ }^{40}$. En su opinión el Estado nada tenía que decir sobre la moral y el dogma cristianos. Sin embargo, la ordenación de la vida política y social del país caía bajo su responsabilidad. Era por tanto necesario el control del clero por parte de las autoridades civiles: «Conviene por tanto que los ministros de la religión nacional dependan lo más que fuere dable de los magistrados, que estos no los pierdan un instante de vista, para cerciorarse del contenido de sus doctrinas» ${ }^{41}$. El aislamiento y hermetismo de los institutos religiosos les hacían sospechosos, a ojos de Marchena, de todo tipo de actividades delictivas y disolventes: «Es cada monasterio un alcázar adonde no puede penetrar la vista de los magistrados, y cada comunidad monástica una sociedad secreta que es dable, y aun presumible, se encuentre en perpetua conspiración contra el gobierno, y que es muy más temible que cualquiera otra asociación misteriosa, porque sus miembros con muy mas apretados vínculos están entre sí ligados» ${ }^{42}$. Ese celo en controlar a los clérigos lo achacaba Marchena al natural funcionamiento del régimen impuesto en España y rechazaba las acusaciones de persecución. Para el abate, «grandes son los derechos que la ley constitucional ha conferido a los ministros de la religión católica, empero por eso mismo no son menores las obligaciones a que los ha sujetado». El modo de actuar de las Cortes había sido perfectamente ajustado a Derecho y además en nada se habían 
desviado de la tradición española. "Tan cierto es que la supresión de las órdenes monásticas en nada excede el coto de la autoridad civil, que nuestros padres y muchos de los que hoy viven, fueron testigos no solo de la supresión del instituto de los jesuitas por la potestad real, mas también del extrañamiento de estos reinos de todos los individuos de esta congregación» ${ }^{43}$.

Tal y como habían hecho tanto ilustrados como románticos, liberales o realistas, Marchena hacía uso del pasado para justificar la legislación revolucionaria. El público, compuesto fundamentalmente por «los profesionales liberales, empleados, militares y comerciantes», probablemente recibió con entusiasmo el mensaje. Sobre este tipo de agrupaciones, Álvaro París Martín apunta que "todas ellas se reunieron en cafés, espacios de sociabilidad frecuentados por los grupos intermedios y surgidos en buena medida como alternativa al ambiente popular imperante en las tabernas ${ }^{44}$.

El discurso de Marchena tuvo repercusiones inmediatas y la sociedad patriótica atravesó una profunda crisis, azuzada por el hostigamiento del capitán general de Andalucía, Juan O’Donojú. El que llegaría pronto a ser el último virrey de Nueva España, con los títulos de jefe político superior y capitán general, debía conocer la fama del abate Marchena y lo trató con cierta severidad. Éste dirigió una encolerizada carta a o'Donojú donde se le acusaba de pasividad ante las acusaciones de herejía que había recibido a cargo de un sacerdote sevillano. También lamentaba Marchena que, en una supuesta reunión secreta, se hubiera decidido expulsarlo de la sociedad constitucional sevillana sin concederle derecho a la defensa. Con ello no solo se dañaba su honor, sino que debilitaba el sistema constitucional ya que Marchena se había limitado a elogiar y glosar un decreto aprobado por las Cortes. Se desconoce cuál fue la reacción de o’Donojú a la recepción de la misiva, pero la expulsión de Marchena se verificó de inmediato ${ }^{45}$.

La tensión fue creciendo a lo largo de 1821 y la opinión pública empezó a polarizarse. El primer enfrentamiento entre grupos armados tendría lugar el 18 de septiembre en Madrid, en la llamada Batalla de Platerías. La represión del tumulto orquestado en la Fontana de Oro y que surgió del intento de los exaltados comuneros de marchar en procesión por el centro de Madrid y de otras ciudades con el retrato de Riego, corrió a cargo de la Milicia Nacional. Algunos testigos vieron en aquellos enfrentamientos callejeros la intentona frustrada de imponer como regente a Juan Romero Alpuente, líder comunero, y someter al rey a su tutela. Según Melchor Ferrer, sin embargo, la regencia la debía de ocupar un triunvirato formado por Riego, Ballesteros y López Baños ${ }^{46}$. En cualquier caso, la conspiración, a juicio del autor de la Relación, quedó irrefutablemente confirmada en la correspondencia y las visitas de destacados miembros de los comuneros a la cárcel de corte, donde estaban presos los seis detenidos tras el motín madrileño ${ }^{47}$.

Aquel gobierno no llegaría nunca a formarse. Sin embargo, sí que se llegó a constituir otro gobierno en la sombra que tuvo como principal objetivo la destrucción del régimen constitucional. Tras las elecciones de marzo de 1822, la victoria del liberalismo exaltado y la creciente crispación provocada por la formación del gobierno dirigido por Evaristo Fernández de San Miguel el 6 de agosto, el día 15 de 1822 se creó la llamada Regencia de Urgel, liderada por el marqués de Mataflorida, el barón de Eroles y el arzobispo de Tarragona. Estos tres individuos se constituyeron en gobierno de la nación, arrogándose la representación del rey llamado "cautivo" y de todo el reino, y 
lanzando un incendiario manifiesto que sentaría las bases de la acción restauradora que meses después ejecutarían las tropas francesas ${ }^{48}$.

La respuesta liberal no se hizo esperar y ese mismo mes aparecía en Madrid un folleto donde se les acusaba de traición. La traición se había perpetrado, en primer lugar, recurriendo a falsas acusaciones de impiedad a los gobiernos constitucionales. Así, la Refutación reproducía secciones del Manifiesto de la Junta donde se acusaba a las autoridades civiles de ir contra la fe y la iglesia católicas: «He aquí como se explica en cuanto al primero: "La Religión de vuestros padres, que se ofreció conservar intacta se halla despojada de sus templos, sus ministros vilipendiados, reducidos a mendicidad, privados de su autoridad y jurisdicción, y tolerados cuantos medios pueden abrir la puerta a la desmoralización y al ateísmo"». Dichos cargos quedaban desmentidos con rotundidad al recordar el contenido de la Carta Magna de 1812: «En ninguna Constitución de cuantas hasta hoy se conocen se ha dado a la Religión, como ley del estado, tanto culto y estabilidad como en nuestra Constitución política. Todo el mundo sabe de memoria, su artículo 12: pero los enemigos de ella afectan siempre olvidarlo» ${ }^{49}$.

En lo relativo a los espacios de culto, de oración y de formación clerical, la Refutación también hacía una defensa cerrada de la racionalidad y la justicia de las medidas adoptadas por los gobernantes liberales desde marzo de 1820: «Bien sé que se debe dar a Dios un culto externo y que nada contribuya él como el decoro y magnificencia de los templos. ¿Mas por eso ha de haber uno en cada esquina? ¿No se ha de guardar proporción entre su número y el número de los fieles? ¿Dios que todo lo crio en peso, número y medida, ha de reprobar que en esto le imiten los hombres? Dios que mandó hacer en Jerusalén solo un templo ¿nos exigirá que tengamos centenares en cada población. ¡Que respondan esos hipócritas ignorantes a esta pregunta! Pues el mantenimiento de los templos y de los que los sirven cuesta; y pues las fuerzas de la nación que ha de hacer el gasto tienen un límite, $-\mathrm{y}$ harto estrecho por desgracia, no es posible que haya más templos que los que se puedan mantener-, ¿y el que se cierren algunos porque no puedan sostenerse, quedando aun muchos más de los que son necesarios atendida la población, es no conservar intacta la Religión? ¿Pues qué no había Religión antes que se hicieran los templos que ahora se cierran?» ${ }^{50}$. Se trataba, por tanto, de hacer un uso óptimo del patrimonio eclesial y de maximizar los recursos públicos para garantizar el único culto protegido y autorizado por las potestades constituidas. El uso de los espacios y los recursos ocupaba el centro de una polémica que había contribuido a convencer a las potencias coaligadas en la Santa Alianza pero sobre todo a la Francia de Luis XVIII a intervenir en la política interna española, y restaurar la plena soberanía regia y los privilegios eclesiásticos para garantizar la estabilidad europea.

\section{Conclusión: templos abiertos, conventos restaurados y otro exilio}

En el invierno de 1822, los absolutistas pudieron confirmar el apoyo del Rey y del ejército de ocupación francés, cuya presencia, a juicio de La Parra, moderó la represión ${ }^{51}$. También conviene también destacar una doble paradoja en torno a la intervención francesa en la España fernandina. En primer lugar, que si en 1808 la invasión napoleónica logró galvanizar la resistencia y unir a los españoles en un esfuerzo de emancipación ampliamente compartido por diversos sectores sociales; en 
1823 el resultado fue el contrario. Con la entrada de las tropas del duque de Angulema se ahondaron las divisiones y la resistencia popular fue mínima. En segundo lugar, como señaló años después un exiliado liberal en Francia, el bogotano Pedro de Urquinaona ${ }^{52}$ : «La España no hubiera visto en aquel año el movimiento simultáneo de los pueblos, ni la resolución marcial de los Merinos, Tapias, Saladares y demás clérigos $\mathrm{y}$ frailes que tomaron las armas, si los franceses no hubieran demolido los conventos y amagado con la reforma del clero (a partir de 1808) $)^{53}$. Por otra parte, el movimiento estuvo acompañado de la campaña oficial de purga y depuración que condujo a un nuevo episodio de exilio a Francia e Inglaterra para una parte importante de los que apoyaron a la Constitución ${ }^{54}$, incluidos muchos clérigos ${ }^{55}$.

Al final de la llamada década ominosa, que tan larga se les debió hacer a los constitucionales, el discurso de los reaccionarios parecía haber calado hondo. Así el regente de la Real Audiencia de Extremadura decía en enero de 1833 que pedía a su público

«Señores, desengañémonos: el espíritu del siglo y el progreso de las luces no es otra cosa que una tendencia á relajar los lazos de toda autoridad religiosa y política. La democracia es el espíritu del siglo porque el orgullo es la pasión de todos los hombres; y el progreso de las luces no es otra cosa que el progreso de la impiedad» ${ }^{56}$.

Del carácter justiciero de aquella restauración teocrática habla claramente el caso de Simón López. El diputado reaccionario a Cortes y desde 1820 obispo de Orihuela, extrañado de España por haberse negado a explicar la Constitución desde el púlpito como decretaron las cortes el 24 de abril, fue enviado a Roma, donde se convirtió en prelado doméstico de Pío VII y en noble romano. A su regreso en 1823 López trataría de ajustar las cuentas con sus perseguidores y para ello resucitar la Inquisición creando las Juntas de Fe bajo el dominio exclusivo de los obispos ordinarios. Al final, lograría saciar sus apetitos regeneradores del alma patria y pasaría tristemente a la historia por incoar el último proceso de ejecución por causa de conciencia, que resultó en la ejecución del profesor heterodoxo Cayetano Ripoll en 1826. Su delito, no haberse descubierto de su sombrero al paso del viático por el valenciano barrio de Ruzafa.

Esa actitud también la compartieron clérigos malcontents en la rebelión catalana antifernandina de 1827. A juicio de Vicente Lafuente, toda una autoridad en la historiografía conservadora decimonónica en España, «hubo algunos regulares comprometidos en los misteriosos cuanto innobles manejos de Cataluña en 1827. Los hubo que después atizaron el fuego de la guerra civil, y aun tomaron parte en ella; pero, ¿habría dejado de hacerse con ellos lo que se hizo aunque hubieran sido liberales en vez de ser realistas? ${ }^{57}$. Ahora bien, el mismo Lafuente enfatiza la gran división que afectaba al clero, y a renglón seguido afirma: «Conventos había en Aragón donde los jóvenes coristas se habían alistado nacionales, y no faltó monasterio en donde, al salir los monjes armados por última vez, hicieron blanco de un San Bernardo que había en la puerta $\aleph^{58}$. Que esos jóvenes seminaristas se hicieran nacionales, es decir, liberales; y que se perpetraran actos de vandalismo anticlerical, dan clara cuenta de las profundas fallas que separaban a las distintas facciones del clero.

Este breve repaso a la participación del clero en la destrucción y en la defensa del sistema constitucional restablecido durante el Trienio Liberal ha tratado de ilustrar precisamente cómo la secularización del discurso y la acción políticas, y el control civil de las instituciones eclesiásticas, manifestó la existencia de profundos desacuerdos entre amplios sectores sociales y eclesiales. La participación en las Cortes, los cafés y las 
calles en la nueva etapa constitucional de una generación que aun recordaba el ardor guerrero desplegado en la guerra contra los franceses, estuvo marcada por el sectarismo y la exclusión del contrario. Con ello, por una parte, se llegaría al recurso a las armas en un periodo breve de tiempo. Por otro, un liberalismo de cortas raíces y sofocado por la cizaña que plantaron sus enemigos fue incapaz de arraigar. El ambiente internacional no fue en absoluto propicio a las reformas eclesiásticas introducidas, y su pésima puesta ejecución, así como la incapacidad para obtener la franca colaboración del monarca en la empresa, fueron también factores determinantes. En cuanto a lo que concierne al clero reaccionario, se abría una década de mayor tranquilidad bajo el ala del absolutismo vencedor. Ahora bien, Fernando VII no se privaría de ejercer sus regalías y de frustrar así los sueños de quienes quisieron ver en su victoria una completa restauración eclesiástica. El rey seguiría exigiendo esfuerzos económicos a la Iglesia por real decreto, incluso en aquel periodo que quedó fuera del tiempo ${ }^{59}$. Como dejó escrito Jean-Philippe Luis en su reseña a la obra de Josep Fontana sobre la segunda restauración fernandina, convendría centrar la atención historiográfica en las contradicciones y mecanismos desplegados por los grupos de poder favorables, o contrarios, al liberalismo constitucional en su propio marco histórico. Y enmarcar el relato en claves de transición, aprendizaje y experimentación con lo nuevo y lo antiguo, en lugar de caer en la tentación narrativa de buscar en sus fracasos los orígenes de éxitos actuales practicando estériles teleologías ${ }^{60}$.

\section{NOTAS}

1. Emilio La Parra López, «Intransigencia y tolerancia religiosa en el primer liberalismo español», Mélanges de la Casa de Velázquez, Vol.44, n.ำ1, 2014, disponible en https:// journals.openedition.org/mcv/5486; Antonio Moliner Prada, «En torno a la Revolución Liberal y la Iglesia española en el siglo XIX», Ler História, n.․9, 2016, disponible en https:// journals.openedition.org/lerhistoria/2475; Manuel Revuelta González, Política religiosa de los Liberales en el siglo XIX. Trienio constitucional. Madrid., CSIC, 1973; Pedro Rújula, Contrarrevolución: realismo y carlismo en Aragón y el Maestrazgo, 1820-1840. Zaragoza, Prensas Universitarias de Zaragoza, 1998; id. Constitución o muerte. El trienio liberal en Aragón y los levantamientos realistas. 1820-1823, Zaragoza, REA, 2000; y William Callahan, Church, Politics and Society in Spain, 1750-1874. Cambridge, Harvard University Press, 1984.

2. Mark Mazover, Governing the World. History of an idea. Londres, Penguin Press, 2012, p. 5-9.

3. Emilio La Parra López, «La restauración de Fernando VII en 1814», Historia Constitucional, n. 15, 2014, p. 205-222. Disponible en https://dialnet.unirioja.es/servlet/articulo?codigo=4782693. Véanse también Antonio Moliner Prada, «El antiliberalismo eclesiástico en la primera restauración absolutista (1814-1820)», Hispania Nova, no 3, 2003, p. 51-73. Disponible en http:// hispanianova.rediris.es/articulos/03_012.htm; José Manuel Cuenca Toribio, «Arias Tejeiro ante la restauración religiosa», Príncipe de Viana, № 100-101, 1965, p. 343-350; o Antoni Sánchez Carcelén, «El retorno al Antiguo Régimen. La restauración absolutista de Fernando VII en Lérida (1814-1820)», Tiempos Modernos, vol. 8, no 28, 2014/1, 27 p. Disponible en http:// www.tiemposmodernos.org/tm3/index.php/tm/article/viewFile/372/414 
4. René Girard, Violence and the Sacred, Baltimore, The Johns Hopkins University Press, 1977 [1972], p. 23.

5. Eduardo de Ontañón, El cura Merino: su vida en folletín. Madrid, Espasa Calpe, 1933, p. 171. Disponible en http://bibliotecadigital.jcyl.es/es/consulta/registro.cmd?id=16244.

6. Véase Pedro Rújula, «Presentación. Recomponer el mundo después de Napoleón. 1814 y las restauraciones», Pasado y memoria: Revista de historia contemporánea, $\mathrm{n}^{\mathrm{o}}$ 13, 2014, p. 11-15.

7. Bo Stråth, Europe's Utopias of Peace: 1815, 1919, 1951, Londres, Bloomsbury, 2016.

8. Emilio La Parra López, Los Cien mil Hijos de San Luis. El ocaso del primer impulso liberal en España, Síntesis, Madrid 2007.

9. Gonzalo Butrón Prida, «From Hope to Defensiveness: The Foreign Policy of a Beleaguered Liberal Spain, 1820-1823». English Historical Review. Vol. CXXXIII, nº 562, 2018, p. 567-597.

10. Juan Luis Simal, «Letters from Spain. The 1820 Revolution and the Liberal International» in Maurizio Isabella y Konstantina Zanou (eds.), Mediterranean diasporas. Politics and Ideas in the long nineteenth century. Londres; Bloomsbury, 2015, p. 25-43, Richard Stites, The four horsemen. Riding to Liberty in Post-Napoleonic Europe, Oxford, Oxford University Press, 2014 y Gregorio Alonso, "A Great People Struggling for Their Liberties': Spain and the Mediterranean in the Eyes of the Benthamites», History of European Ideas, no 41, v. 2, 2015, p. 194-204.

11. Benito Pérez Galdos, Los cien mil hijos de San Luis, Linkgua Digital, Barcelona, 2018 (1877), p. 30.

12. Melchor Ferrer, Domingo Tejera y José F. Acedo, Historia del Tradicionalismo Español. Sevilla, Ed. Trajano, 1942, t. 2, p. 243. En cuanto a la novedad respecto al Antiguo Régimen, contradicciones y limitaciones de la alianza del Altar y el Trono véase Andoni Artola Renedo, «La alianza imposible. Los obispos y el Estado (1814-1833)», 2013. halshs00918404. Disponible en https:// halshs.archives-ouvertes.fr/halshs-00918404. El distanciamiento respecto a la camarilla regia de eclesiásticos tan señeros de la contrarrevolución como Blas de Ostolaza, Juan de Escoiquiz y el Nuncio Pontificio Pietro Gravina a partir de 1814 en Emilio La Parra López, Fernando VII. Un rey deseado y detestado. Barcelona, Tusquets, 2018, p. 317.

13. Juan Buelga y Solís, Prevención contra los enemigos ocultos del Estado y de la Religión. Predicado en la catedral de esta ciudad el día 6 de enero de este año, en presencia del Excmo. Sr. Obispo, y de los Cabildos Eclesiástico y Secular por el licenciado Juan Buelga, Málaga, 1820, p. 9. 14. Id., p. 14.

15. Juan Buelga y Solís, Manifiesto de las persecuciones que durante el gobierno revolucionario sufrió Don Juan de la Buelga y Solís, canónigo lectoral de Santa Iglesia Catedral de Málaga, en que además se exponen varios principios y hechos de los demagogos, Málaga, Imp. Francisco Martínez de Aguilar, 1824, p. 1. Disponible en http://

www.bibliotecavirtualdeandalucia.es/catalogo/consulta/registro.cmd?id=1013891

16. Melchor Ferrer, Domingo Tejera y José F. Acedo, Historia del tradicionalismo español, op. cit, t. 3, 1942 , p. 26.

17. José Ángel Echeverria, «Los capuchinos hispanos ante la reforma eclesiástica del trienio liberal, y la restauración posterior (1820-1833)», Laurentianum, no 40, 1999, p. 3-166.

18. Véanse, entre otros, El liberal arrepentido o confesión general práctica, en la que se tratan todas las materias en las que puede haber delinquido un liberal revolucionario. La publica P.F.M.R.D para la instrucción de los confesores, y facilitar el examen de conciencia a los revolucionarios que, arrepentidos de sus culpas, desean sinceramente convertirse a Dios, y salir 
de tan infeliz estado, Joaquín Puigrubí, Tortosa, 1824; o las nueve Cartas del Liberal Arrepentido a su amigo Fulgencio, Joaquín Puigrubí, Tortosa, 1824. Análisis de estos documentos en Gónzalo Álvarez Chillida, El antisemitismo en España: la imagen del judío, 1812-2002. Madrid, Marcial Pons, 2002, p. 107-108; y Gaspar Feliù i Montfort, La clerecia catalana durant el Trienni Liberal, Barcelona, Institut d'Estudis Catalans, 1972, p. 184-190. 19. Véase Álvaro París Martín, «Política popular en Madrid en la crisis del Antiguo Régimen (1780-1834)», en Ricardo Franch Benavent et al. (eds.), Cambios y Resistencias Sociales en la Edad Moderna. Un análisis comparativo entre el centro y la periferia mediterránea de la Monarquía Hispánica, Madrid, Sílex, 2014, p. 119-130. Para el caso francés puede verse Emmanuel Fureix y François Jarrige, La modernité désenchantée. Relire l'histoire du XIX ${ }^{e}$ siècle français, Paris, La Découverte, 2015, citado en Álvaro París Martín, «Los voluntarios realistas en Madrid: politización popular y violencia contrarrevolucionaria (1823-1833)», en Pedro Rújula y Javier Ramón Solans (eds.), El desafío de la revolución. Reaccionarios, antiliberales y contrarrevolucionarios (siglos XVIII y XIX). Granada, Comares, 2017, p. 89-106 y 89.

20. Gérard Dufour (ed.), Sermones revolucionarios del Trienio Liberal, Alicante, Instituto de cultura Juan Gil-Albert, 1991.

21. Puede verse Gregorio Alonso García, La nación en capilla. Ciudadanía católica y cuestión religiosa en España, Granada, Comares, 2014, p. 41-97. Para el caso gallego, José Antonio Vázquez Vilanova, «El clero liberal de la diócesis compostelana durante la primera mitad del siglo XIX: análisis e interpretación de un fenómeno peculiar», Cuadernos de Estudios Gallegos, vol. 48, no 114, 2001, p. 161-180. Disponible en http:// estudiosgallegos.revistas.csic.es/index.php/estudiosgallegos/article/view/147. 22. Juan Francisco Fuentes, «Marchena, 'anarquista'. Liberalismo exaltado y jacobinismo en el Trienio Liberal», Revista de História das Ideias, 1988, ํํ10, p. 307-317 e id. José Marchena: vida política e intelectual, Barcelona, Crítica, 1989. Un examen local de las reformas y su relación con la situación de la Hacienda en Ricardo Montolío Hernández, «La reforma de la dotación de culto y clero en el Trienio Liberal (1820-1823). Toledo», Espacio. Tiempo y Forma. Serie V. Historia Contemporánea, no 14, 2001, p. 34-55.

23. José Marchena, Discurso sobre la ley relativa a la extinción de monacales y reforma de regulares, Sevilla, Imp. de Caro, 1820, p. 3.

24. Id. p. 4.

25. Melchor Ferrer, Domingo Tejera y José F. Acedo, Historia del tradicionalismo español, op. ci., t. II, p. 30.

26. Id. p. 30.

27. Se trataba de «El grito de un español verdadero a toda la nación española», «Del general ruso al ejército que ha de venir a España», y «Extracto de la Gaceta de Múnich de 19 de noviembre de 1820 ».

28. «El asesinato del Matías Vinuesa, cura de Tamajón: Crimen absolutista que terminan pagando los liberales», en http://www.ruizjimenez.es/ficheros/ articulos_marta/asesinato_cura_de_tamajon.pdf

29. Elisabel Larriba, El público de la prensa en España a finales del siglo XVIII (1781-1808), Zaragoza, Prensas de la Universidad de Zaragoza, 2013. Véase también su artículo «Mejor que el púlpito: la prensa. El Padre Traggia y El Vencedor católico (1809-1810)», El Argonauta español, no 9, 2012. Disponible en http:// argonauta.revues.org/770

30. El ciudadano despreocupado, 1, Sevilla, Imprenta de Padrino, 1820, p. 1-2. 
31. Id, t. 2, p. 8.

32. Id., p. 4.

33. Id., p. 2.

34. Id., p. 4.

35. Id. El énfasis en el original.

36. Colección eclesiástica española comprensiva de los breves de s. S., notas del m. R. Nuncio, representaciones de los ss. Obispos á las cortes, pastorales, Edictos, \&c. con otros documentos relativos á las innovaciones hechas por los constitucionales en materias eclesiásticas desde el 7 de marzo de 1820. Madrid, Imprenta de Aguado, 1823, p. 12-14, p. 13.

37. Héctor Ávalos, Fighting words: the origins of religious violence, New York, Prometheus, 2005; William T. Canavagauh, «Does religion cause violence? Behind the question lies a morass of unclear thinking», Harvard Divinity Bulletin, vol. 35, no 1-2, 2007, p. 1-16; Timothy Fitzgerald, "Critical religion and critical research on religion: Religion and politics as modern fictions», Critical research on religion, vol. 3, no 3, 2015, p. 303-319; Didier Girard. La violenza e il sacro, Milán, Abelphi, 1992; y Dario Martínez Morales, «Violencia y religión, Cuestiones Teológicas, vol. 33, nº 79, 2006, p. 55-68.

38. Barbara Ehrenreich, Rites of Blood. The Origins and History of the Passions of War, Londres, Virago, 1998.

39. Eduardo de Ontañón, El cura Merino. Su vida en folletín, Madrid, Espasa Calpe, 1933, p. 204. También puede leerse Esteban Ibáñez, «El Cura Merino, sacerdote y cruzado de España», Boletín de la Institución Fernán González, vol. 171, 1968, p. 283-304.

40. Discurso sobre la ley relativa a la extinción de monacales y reforma de regulares, op. cit., p. 6.

41. Id., p. 12.

42. Id., p. 13.

43. Id., p. 13-14.

44. Álvaro París Martín, «Artesanos y política en Madrid durante el irresistible ascenso del liberalismo (1808-1833)», Revista THEOMAI / THEOMAI Journal. Estudios críticos sobre Sociedad y Desarrollo / Critical Studies about Society and Development, no 31, 2015, p. 43-62 y 55.

45. La carta la reprodujo El Constitucional, o sea crónica científica, literaria y política, el 29 de diciembre de 1820. Francisco Javier Fuentes ofrece una detallada valoración del texto en el citado artículo de 1988, p. 313-314.

46. Melchor Ferrer et al., Historia del Tradicionalismo español, op. cit., t. 2, p. 36.

47. Relación histórica de la Batalla de Platerías de D.S.M., Madrid, Imp de Núñez, 1823, p. 22-23.

48. Una copia del manifiesto en http://www.historiacontemporanea.com/pages/ bloque5/la-restauracion-del-absolutismo-18141833/documentos_historicos/ manifiesto-de-la-regencia-de-urgel-en-apoyo-de-fernando-vii?theme=pdf. Un detallado examen puede encontrarse en la Tesis Doctoral de Ramón Arnabat Mata, Revolució e contrarevolució en Catalunya durant el Trienni Liberal (1820-1823), Universitat Pompeu i Fabra, 1999. Disponible en ww.tdx.cat/TDX-0722109-132407

49. Refutación de un manifiesto publicado en Urgel por tres traidores que han osado titularse Regencia de España. Escríbela un amante de la Constitución, ni más, ni menos. Madrid, Imp. que fue de García por su Regente D. Manuel Pita de la Vega, 1822, p. 4. Disponible en http://digibuo.uniovi.es/dspace/handle/10651/3191

50. Ibid., p. 5-6.

51. Emilio La Parra López, Los Cien Mil hijos de San Luis. Passim.

52. Rosario González Sabariegos, «Pedro de Urquinaona y Pardo. (Un colombiano al servicio de España)», Revista de Indias, nos 77-78, 1959, p. 435-448. 
53. Pedro de Urquinaona, La España bajo el poder arbitrario de la congregación apostólica, Madrid, Imp. Fernández Angulo, 1835, 3ª ed., p. 36.

54. Véanse, entre otros, Vicente Llorens, Liberales y Románticos. Una emigración española en Inglaterra (1823-1834), Colegio de México, México, 1952; Rafael Sánchez Mantero, Liberales en el exilio: la emigración política en Francia en la crisis del Antiguo Régimen, Madrid, Rialp, 1975; o Juan Luis Simal, Emigrados. España y el exilio internacional, 1814-1834, Madrid, Centro de Estudios Políticos y Constitucionales, 2012.

55. Germán Ramírez Aledón, «El clero español en el exilio londinense», en Daniel Muñoz Sempere y Gregorio Alonso García (eds.), Londres y el liberalismo hispánico, Iberoamericana/Vervuert, Madrid-Frankfurt am Main, 2011, p. 35-59 y Aline Vauchelle, «La emigración a Francia del clero liberal español», Brocar, Universidad de la Rioja, n² 21, 1998, p. 269-309.

56. Discurso pronunciado en la Real Audiencia de Extremadura el día 2 de enero de 1833, por su regente el Señor Barón de Juras Reales (Luis María Moxó y López Francoli), Burgos, Imp. de D. R. Villanueva, p. 15.

57. Vicente de la Fuente, Historia de las sociedades secretas antiguas y modernas en España y especialmente de la Francmasoneria, Valladolid, Maxtor, 2012 (1870), vol. I, p. 56.

58. Ibid., p. 56-57.

59. Josep Fontana, De en medio del tiempo. La segunda restauración española, 1823-1834, Barcelona, Crítica, 2006,

60. Jean-Philippe Luis, «Josep Fontana, De en medio del tiempo», Mélanges de la Casa de Velázquez [En línea], nº 38-1, 2008, http://mcv.revues.org/1131.

\section{RESÚMENES}

En este artículo se reflexiona sobre las reacciones del clero católico durante los primeros momentos del periodo constitucional en España teniendo en cuenta la creciente literatura historiográfica sobre la diversidad de sus opciones políticas. El trabajo se centra en los espacios y los medios de comunicación empleados por los destacados sacerdotes y predicadores que se opusieron a las reformas eclesiales ejecutadas durante el Trienio Liberal. A continuación se analizan las aportaciones al debate realizadas por algunas figuras cuyas actitudes escapan una fácil identificación con los términos "reaccionario" o "liberal". En la última sección se ofrece un innovador análisis de las intervenciones del clero anti-constitucional en el marco internacional que se generó a partir de la fundación de la Santa Alianza, liderada por Francia, Prusia y Rusia, y que se enfrentó activamente a las innovaciones políticas que se dieron en España entre 1820 y 1823.

Cet article offre une réflexion sur les réactions du clergé catholique dans les premiers temps de la période constitutionnelle en Espagne en tenant compte de la croissante production historiographique sur ses options politiques. Cette étude est tout d'abord centrée sur les espaces et les moyens de communication employés par les prêtres et prédicateurs opposés aux réformes ecclésiales entreprises pendant le Triennat libéral. Sont ensuite analysés les apports au débat de certains personnages qui, de par leur attitude, ne peuvent être aisément qualifiés de "réactionnaires" ou de «libéraux». La dernière section offre une innovante analyse des interventions du clergé anticonstitutionnel à l'échelle internationale suite à la mise en place de la 
Sainte Alliance, conduite par la France, la Prusse et la Russie, qui s'opposa activement aux innovations politiques qui se produisirent en Espagne entre 1820 et 1823.

Relying on the growing historiographical work on the multifarious political roles played by the Spanish clergy in the first stages of constitutional rule in Spain, this paper explores some key contributions made by relevant members of the Catholic clergy. The text pays attention to the spaces and the media used by those priests who opposed and endorsed the administrative reforms of the Catholic Church during the Liberal Triennium. Second, it highlights the attitudes and political discourses of certain clerics which defied the often over-simplifying labels of 'reactionary' and 'Liberal'. The last section sheds new light on the discursive interventions carried out by outstanding anti-constitutional clergymen within the international context set by the recreation of the counter-revolutionary Holy Alliance, spearheaded by France, Prussia and Russia, which actively opposed the political innovations experienced in Spain between 1820 and 1823.

\section{ÍNDICE}

Palabras claves: Revolución y contrarrevolución, clero católico, espacios politizados, Trienio liberal

Keywords: Revolution and counter-revolution, Catholic clergy, politicised spaces, Trienio liberal Mots-clés: Révolution et contrerévolution, clergé catholique, espaces politisés, Trienio liberal

\section{AUTOR}

\section{GREGORIO ALONSO}

University of Leeds 